\title{
INTERthesis
}

\section{ENTRE ESPÉCIES E CIÊNCIAS: UMA REFLEXÃO SOBRE A UTILIZAÇÃO DE ARGUMENTOS CIENTÍFICOS PARA LEGITIMAÇÃO DA CAUSA ANIMAL}

\author{
Eveline Teixeira Baptistella ${ }^{1}$ \\ Juliana Abonizio ${ }^{2}$
}

\section{Resumo:}

O conhecimento científico estabelece-se, ao longo da modernidade, como o único conhecimento verdadeiro e vários princípios fundamentam suas práticas, dentre os quais destacamos o objetivo de dominação da natureza, a certeza na supremacia da espécie humana diante das demais e a validade epistemológica do fato. Não obstante, as descobertas realizadas pela ciência possibilitaram o questionamento de alguns de seus próprios fundamentos, como a superioridade dos humanos, e, assim, engendraram o desenvolvimento de argumentos de defesa dos animais baseados também em fatos. Dentro desse contexto, o objetivo deste trabalho é refletir sobre como a construção de um conhecimento sobre animais e suas relações com humanos têm contribuído para transformações dos embasamentos éticos que subjazem às ações cotidianas. Através da análise do caso do cão Scooby, vemos que, apesar das transformações supracitadas, a vida humana tem o privilégio diante das vidas das demais espécies.

Palavras-chave: Humanidades. Estudos animais. Direitos animais. Cultura científica.

\section{INTRODUÇÃO}

Para provar que um animal sente dor, Chuahy (2009, p.20) cita um teste de laboratório realizado pela Escola de Ciências Biológicas da Universidade de Liverpool, que demonstra comportamentos associados à dor. Ao ser queimado, um ser vivo afasta a parte do corpo que está na chama. Também pode chorar, gritar, pedir ajuda ou limitar o uso de partes do corpo machucadas. Vertebrados e alguns invertebrados apresentam tais comportamentos nos testes. Segue-se a conclusão: "Já que os animais vertebrados têm uma estrutura neurológica e o comportamento

\footnotetext{
1 Mestre em Estudos de Cultura Contemporânea pela Universidade Federal do Mato Grosso. Professora do Departamento de Comunicação Social da Universidade Estadual de Mato Grosso, Alto Araguaia, MT, Brasil. E-mail: evelbap@gmail.com

2 Doutora em Sociologia pela Universidade Estadual Paulista Júlio de Mesquita Filho. Professora da Universidade Federal de Mato Grosso no Programa de Pós-Graduação Estudos de Cultura Contemporânea em Cuiabá, MT Brasil. E-mail: abonizio.juliana@gmail.com
}

R. Inter. Interdisc. INTERthesis, Florianópolis, v.13, n.2, p.76-105 Mai-Ago. 2016 
diante da dor parecidos com o nosso, acredita-se que eles também têm a habilidade de sentir e sofrer" (CHUAHY, 2009, p.21).

Para nossa reflexão, o resultado do trabalho é menos importante do que a maneira como ele foi descrito. Apesar de o animal demonstrar comportamento idêntico ao de qualquer ser humano com dor, a autora tem a cautela de escrever que "acredita-se" que os não-humanos sentem e sofrem. É revelador que se trate de um livro que se chama "Manifesto pelos direitos dos animais", o que daria a autora alguma liberdade para conferir aos bichos, cujos direitos procura defender, o benefício da afirmação de que eles, de fato, são capazes de sentimentos, coisa que qualquer pessoa que convive um animal de estimação poderia afirmar sem hesitar.

É possível atribuir o cuidado da autora à preocupação em oferecer uma análise imparcial, amparada estritamente em dados cientificamente comprovados. É uma postura adotada para garantir a credibilidade. As questões morais e éticas apoiam-se na retórica científica que, apesar de basear-se na dúvida - afinal, apenas acredita-se que o bicho tem dor - tem estatuto de verdade. Pensando nesta questão, propusemo-nos a refletir sobre as relações entre humanos e não-humanos, questionando os códigos éticos que guiam essas relações e as bases científicas que os fundamentam.

O relacionamento de humanos com os animais tem diversas facetas e entre elas estão o afeto e a empatia, sentimentos que impulsionam os movimentos de defesa. Estes aspectos, no entanto, não são plenamente reconhecidos quando se trata de argumentar em prol de políticas de proteção animal, uma vez que, conforme Francione (2013), em nossa sociedade o bem-estar humano é sempre sobreposto ao de outras formas de vida.

Assim, este trabalho teve como ponto de partida um questionamento: por que os movimentos de proteção, apesar de defenderem o valor intrínseco das vidas dos animais não-humanos, embasam seus discursos prioritariamente em dados científicos - como pesquisas que mostram as capacidades cognitivas dos animais e não apenas nos argumentos éticos?

Nossa hipótese é que algumas heranças da modernidade operaram nesse modelo de argumentação adotado pelos ativistas da causa, em especial a dicotomia 
entre fato e valor e a supervalorização da ciência. A partir daí, através de revisão bibliográfica e análise de um episódio específico, o caso do cão Scooby, explicitado mais adiante, buscamos investigar as implicações destes conceitos nas relações entre homens e animais, mostrando o processo pelo qual os dados científicos, notoriamente utilizados para justificar a dominação dos bichos, passam a ser usados no sentido contrário, como instrumentos de persuasão para conferir ou ampliar os direitos concedidos aos animais em nossa sociedade.

\section{A DICOTOMIA FATO/VALOR E O SURGIMENTO DO MOVIMENTO DE PROTEÇÃO ANIMAL}

A pesquisa Trust Barometer 2015, realizada pela Edelman, maior empresa de relações públicas do mundo, demonstrou os níveis de confiança que uma pessoa comum depositaria no porta-voz de uma empresa, levando em conta a formação profissional dele, e comprovou que acadêmicos e especialistas lideraram o ranking global, com $70 \%$ da confiança dos entrevistados, em $2^{\circ}$ lugar vieram os especialistas técnicos, com $67 \%$. No Brasil, o resultado é diferente, mas os níveis de credibilidade são maiores. Apesar das pessoas comuns ficarem em $1^{\circ}$ lugar, com $84 \%$, o índice de confiabilidade de especialistas e acadêmicos é quase o mesmo: $83 \%$. (TRUST BAROMETER, 2015)

Chalmers (1993) mostra que as raízes dessa confiança, embora questionáveis, remontam aos primórdios da ciência moderna e se estendem à mídia e ao senso comum. "A ciência deve parte de sua alta estima ao fato de ser vista como a religião moderna, desempenhando um papel similar ao que desempenhou o cristianismo na Europa em Eras Antigas" (CHALMERS, 1993, p.14). Esta crença parte da premissa de que o saber científico, obtido da observação e coleta de dados seria não apenas mais confiável, mas representaria a verdade. A verdade estava localizada no mundo natural a ser desvendado através do método científico. Só posteriormente, por exemplo, a sociologia foi criada visando despender os mesmos rigor e método dedicados ao mundo das representações. Segundo Comte (1978), criador do Positivismo, a sociologia coroaria o desenvolvimento das ciências. A 
tentativa de construir um conhecimento científico sobre a sociedade, a cultura e as criações humanas baseava-se nos métodos já utilizados pelas demais ciências, as chamadas naturais, o que opera como uma hierarquia entre os saberes e uma distinção entre o mundo natural e o dos costumes, sendo que $\circ$ primeiro representaria a razão pura. Tais demarcações e hierarquias entre saberes começam a se delinear, como exemplifica Chauí (2013, p.11), desde o período do Renascimento. Havia "[...] a preferência pelas discussões em torno da clara separação entre fé e razão, natureza e religião, política e Igreja" (CHAUÍ, 2013, p.11). O processo de diferenciação entre dois tipos de saber se completaria na modernidade: resultaria na divisão entre humanidades, representadas pelo trivium, e ciências, as artes do quadrivium (ALMEIDA, 2007, p.3).

Mariconda (2006, p.454) situa essa separação na perspectiva da dicotomia entre fato e valor, uma condição central do pensamento moderno, que se mantém nos dias atuais. "Em suma, as questões acerca de valores são questões subjetivas e podem ser consideradas como meras questões de preferências individuais" (MARICONDA, 2006, p.454). Já o fato carrega o selo da

[...] o por um método autônomo suficiente, método que se assenta fundamentalmente naquilo que é dado aos humanos pela própria natureza (ou que é inerente à sua própria natureza humana) e que constitui a sua razão natural, ou seja, os sentidos, o intelecto e a linguagem (a capacidade linguística de comunicação) (MARICONDA, 2006, p.454).

As disciplinas do quadrivium estariam ligadas aos fatos e as do trivium à esfera dos valores. Na consolidação da ciência moderna, o valor foi relegado a uma posição inferior, pois seria ligado às paixões, sendo, eminentemente, irracional. Já os fatos estariam do lado da razão que, até hoje, é considerada por muitos uma qualidade exclusiva dos humanos.

No mundo acadêmico, o valor seria ligado às humanidades enquanto os fatos seriam domínio das ciências, ainda que as primeiras neguem e busquem adentrar o campo cientifico para se legitimar no mesmo pela utilização de métodos similares. Conforme Chalmers (1993), diversas áreas de estudo, inclusive, se pautam pelo método empírico e buscam quantificar resultados como forma de comprovar a validade do saber obtido. Porém, as tentativas de aproximação não se efetivam, já que se trata de duas mentalidades diferentes que se expressam na prática da 
pesquisa, "[...] podem ser vistas como modulações da inteligência do que pode ser a realidade e o imaginário, do visível e invisível [...]" (IANNI, 2003, p.5).

O preconceito com a subjetividade persiste e o cientista é instado a se afastar das emoções, pois elas prejudicariam a tarefa de encontrar a verdade, ou seja, o fato. A associação entre descobertas científicas e fatos é difundida no senso comum, razão pela qual os publicitários lançam tanta mão da autoridade dos especialistas.

Anúncios frequentemente asseguram que um produto específico foi cientificamente comprovado como sendo mais branqueador, mais potente, mais sexualmente atraente ou de alguma maneira preferível aos produtos concorrentes. Assim fazendo, eles esperam insinuar que sua afirmação é particularmente bem fundamentada e talvez esteja além de contestação (CHALMERS, 1993, p.12).

Contudo, a própria ciência questiona atualmente a distinção que engendrou. Por exemplo, o filósofo estadunidense Hilary Putnam, no livro "The Collapse of the Fact/Value Dichotomy and Ohter Essays", publicado em 2002, argumenta que não existe uma dicotomia rígida entre fato e valor, mas sim um entrelaçamento, uma indissociabilidade entre ambos os termos. A ciência, tal qual toda atividade humana, contém valores e, ainda que possamos separar valores epistêmicos de juízos de valor, a neutralidade e imparcialidade advogadas não são senão ficções. As próprias concepções de objetividade e coerência são valores epistêmicos. Já a normatividade está presente, por exemplo, na escolha por tal ou qual termo para descrever o que se objetiva. O autor dá o exemplo do termo "cruel" que serve para descrição, mas também implica em julgamento de alguma atividade como cruel.

Referindo-nos ao tema desta reflexão, a relação entre humanos e demais animais, vemos que a busca pela verdade não era de todo objetiva como se propunha ser, pois estava fundada em uma crença - a supremacia da humanidade e em um princípio - sua finalidade era o benefício humano e a dominação da natureza ${ }^{3}$. Cada um desses aspectos passa a ser questionado com as novas

\footnotetext{
3 Segundo Merchant (1991), a ciência e o progresso baseado no desenvolvimento implicam na dominação e subjugação da natureza e da mulher. Para a autora, a revolução científica moderna substituiu a metáfora da terra como uma mãe provedora e um organismo vivo por uma visão mecanicista. Também difundiu a imagem da natureza como um elemento descontrolado, que
} 
descobertas da própria ciência, além de novas propostas, como os estudos decoloniais e estudos feministas, o que levou a uma revisão das diferenças e semelhanças entre homens e animais e a consequente revisão dos lugares que ocupam socialmente, abrindo espaço para movimentos articulados em favor do estabelecimento de direitos aos animais e de deveres humanos para com eles.

\subsection{SUPREMACIA DA HUMANIDADE}

Ao longo da história, é possível notar uma busca incessante por diferenciar o homem dos outros animais. Para Ingold (1994), desde a antiguidade clássica o conceito de animalidade é oposto ao de humanidade como forma de criar a imagem que o homem ocidental tem de si.

$\mathrm{Na}$ modernidade, este mecanismo podia ser percebido em diversas instâncias. Na análise de Thomas (2010), eram várias as maneiras de colocar os humanos em um status elevado, seja como hierarquicamente superiores ou até mesmo completamente distintos do resto da criação. Entre os critérios de diferenciação utilizados estavam beleza, capacidade de falar, existência de alma e capacidade de escolha como atributos humanos. O fator preponderante não era o que os homens tinham, mas aquilo que faltava aos animais. O ser humano tinha razão. Os animais, no máximo, instintos e, algumas vezes, nem isso. $O$ representante mais forte desse modelo de pensamento foi René Descartes, que, em 1630, divulgou a tese de que os animais são autômatos incapazes de pensar e de ter sensações (THOMAS, 2010, p.43). Apesar de semelhanças inegáveis entre homens e animais, somente os primeiros teriam mente, o que lhes daria atributos como capacidade de sentir dor e livre-arbítrio, além de consciência, moral e ética.

A suposta incapacidade dos animais em sentir serviria como justificativa para todo tipo de abuso. Se um bicho não sente dor, não há mal em fazê-lo trabalhar à exaustão ou praticar "esportes" como rinhas, açulamentos e caçadas. O terreno para a experimentação científica estava aberto: em nome da nascente ciência, não

representaria diversos riscos para os humanos, e, com isso, fortalecendo o discurso de controle do mundo natural, promovendo a separação entre natureza e cultura.

R. Inter. Interdisc. INTERthesis, Florianópolis, v.13, n.2, p.76-105 Mai-Ago. 2016 
representava dano a ninguém submeter animais a condições hoje vistas como degradantes por ativistas. Para Thomas (2010, p. 45), Descartes não institucionalizou a crueldade contra os animais, mas não há risco em dizer que ele a absolveu.

[...] o mais forte argumento, em favor da posição cartesiana, era que ela constituía a melhor racionalização possível para o modo como o homem realmente tratava os animais. A visão alternativa deixava espaço para a culpa do homem [...] (THOMAS, 2010, p.45).

Nesse ponto, é possível dizer que Descartes, ao justificar a degradação dos animais, também forneceu elementos para um movimento contrário. "A negação cartesiana da alma dos animais gerou vasta literatura erudita; não exageramos ao descrevê-la como uma das preocupações centrais dos intelectuais europeus dos séculos XVII e XVIII" (THOMAS, 2010, p.45).

O embate entre valor e fato era claro. Descartes dispunha do método e de sua natureza intelectual superior para dizer que os animais não passavam de objetos animados. Ele tinha fatos. Mas qualquer um que convivesse com um animal poderia dizer o contrário, considerando apenas a sua percepção cotidiana e os seus sentimentos, ou seja, aquelas características que estão diretamente colocadas na escala dos valores.

Ainda em 1650, Margareth Cavendish, duquesa de Newcastle, defendia a capacidade que os animais teriam de sentir e, em fins do século XVII, grupos sociais da Inglaterra atacavam os maus tratos aos animais (THOMAS, 2010, p.153). A indignação contra o pensamento originalmente formulado por Descartes fermentou a contestação à crueldade contra os bichos.

Voltaire, em seu "Dicionário Filosófico", de 1764, claramente se dirige aos partidários das ideias cartesianas sobre os animais.

Bárbaros agarram esse cão, que tão prodigiosamente vence o homem em amizade, pregam-no em cima de uma mesa e dissecam-no vivo para mostrar-te suas veias mesaraicas. Descobres nele todos os mesmos órgãos de sentimento de que te gabas. Responde-me, maquinista, teria a natureza entrosado nesse animal todos os elatérios do sentimento sem objetivo algum? Terá nervos para ser insensível? Não inquines à natureza tão impertinente contradição (VOLTAIRE, 2001, p.309).

Para tal posição, Voltaire contou com a ajuda da observação científica. Se a anatomia de humanos e não-humanos é tão parecida, não seria possível que o 
restante fosse tão diferente. Conforme Thomas (2010), a capacidade de sentir e pensar dos animais era muito clara para aqueles que conviviam com eles no cotidiano. No entanto, esta percepção era atribuída como valor. O que Voltaire faz, então, é utilizar de procedimentos científicos para ratificar sua posição contra a crueldade para com os animais.

Os avanços científicos que se beneficiaram da experimentação animal também começavam a servir de base para um movimento de proteção. Neste momento, vemos o entrecruzamento das posições embasadas em fatos e em valores. Se maltratar animais podia ser visto como moralmente errado para quem tivesse alguma sensibilidade dirigida às suas vidas, era considerado, todavia, cientificamente correto.

No entanto, as descobertas científicas - que certamente causaram dor e morte - trazem a dúvida sobre sua própria prática. Desse modo, considerar a provocação de dor um erro do ponto de vista moral passa a ter respaldo científico e assim, aqueles que questionavam a afirmação científica sobre a insensibilidade animal passaram a se valer da própria ciência para sustentar seus argumentos. As disputas por determinada posição dão-se no terreno cientifico e, mesmo antagônicas, valem-se do mesmo recurso: inegabilidade do fato.

\subsection{O MOVIMENTO DE PROTEÇÃO ANIMAL}

Maltratar ou bem tratar animais não foram posturas criadas na modernidade, mas não resta dúvida que elas foram intensificadas nesse período. O sofrimento de outras formas de vida é ingrediente da nossa alimentação, vestimenta, entretenimento e medicação. Tais práticas, presentes nos padrões de comportamento de diversas sociedades humanas, encontraram amparo nas premissas da ciência moderna, que tornava a crueldade contra os animais justificada a partir da necessidade de promover o bem-estar humano. Merchant (1991, p. 170) lembra que a mudança de mentalidade, que culmina no chamado mundo moderno, estava diretamente relacionada a mudanças de comportamento em relação à natureza e ajudava a impulsionar o processo de incremento do comércio e da 
industrialização. É possível notar, inclusive, que os próprios bichos viriam a se tornar peças dessas engrenagens a partir da expansão da produção de carne em escala cada vez maior e mecanizada, praticamente eliminando a convivência do humano com os animais que serão mortos e transformados em produtos cárneos.

O maltrato aos animais feria sensibilidades, mas não interferia na razão, o domínio mais importante. Para se chegar aos fatos científicos é preciso matar animais, o que não era objetado por princípios éticos, uma vez que a ética está somente na esfera humana.

A crueldade contra os bichos, segundo Pinker (2013, p. 115), era - e podemos dizer que ainda é - então institucionalizada em diversos tipos de sociedades humanas. Na Europa, até o lazer era baseado na exploração dos animais. Pesca, caça e até torneios em que gatos eram mortos a cabeçadas eram práticas tratadas como esporte.

As primeiras leis de proteção animal surgiram somente em 1822, na Inglaterra. Pouco tempo depois, o movimento de proteção aos animais foi oficialmente fundado. Em 1824, era criada a Sociedade pela Prevenção da Crueldade com os Animais - 35 anos antes do lançamento de "A origem das espécies", de Charles Darwin. É verdade que, para a maioria dessas pessoas, a proteção do animal vinha condicionada ao bem-estar humano, pois este parecia a única justificativa cabível para que fosse dada atenção às condições de vida de criaturas inferiores. Naqueles dias, buscar direitos para um animal era considerado até mesmo uma piada - uma piada que, entretanto, não durou muito tempo. O poder do vínculo entre espécies fez com que os bichos mais próximos da família humana fossem logo incluídos na rede de proteção legal.

Em 1821, quando o Parlamento britânico examinou a primeira dessas medidas - uma proibição dos maus-tratos contra cavalos -, provocou acessos de riso em parlamentares e comentários de que ela conduziria à proteção de cães e até de gatos. Dentro de duas décadas foi exatamente o que aconteceu (Pinker, 2013, p.12345).

Cães e gatos, indubitavelmente, encontraram um espaço cada vez maior no círculo afetivo humano e podem ser consideradas espécies privilegiadas. Hoje, existe até mesmo o termo pet para se referir aos animais de estimação. Dados da Câmara Setorial Pet Brasileira (O MERCADO, 2013) mostram que o Brasil tem 106 
milhões de pets e é o $2^{\circ}$ mercado mais lucrativo do planeta. Os animais citados no levantamento são apenas aqueles cuidados por uma família.

Mas o que dizer das galinhas, bois e porcos mortos todos os anos pela indústria alimentícia? O que falar dos ratos, macacos e coelhos confinados em laboratórios? Como exigir que tenham direitos quando a morte e a dor deles quando admitidas - são apresentadas como essenciais para nossa sobrevivência? Estes são dados que o movimento de proteção animal leva em conta ao construir seu discurso. Se os primeiros protetores europeus sabiam da importância de colocar em relevo o bem-estar humano para garantirem suas conquistas, os ativistas do século XX e XXI também reconhecem a necessidade de apresentar informações que permitam atingir seus objetivos.

Ainda hoje os valores estão colocados abaixo da razão. Convencer alguém que um animal merece respeito ou proteção apenas baseado em sentimentos acaba, então, sendo um argumento fraco - uma vez que está elencado no âmbito da emotividade. Um livro sobre a amizade entre um menino e um cão, por exemplo, pode ser comovente, mas uma obra do gênero tem pouco ou nenhum impacto na criação de políticas públicas em prol dos bichos. No entanto, uma única pessoa tocada por esta obra - ou, o que é mais frequente, sensibilizada pela amizade que desenvolveu com um animal - pode vir a articular ações que contribuam para mudanças nos padrões de tratamento dos animais não-humanos.

Mas, neste caso, parte de seu sucesso certamente recairá em sua habilidade de utilizar argumentos científicos na defesa de sua posição e ganhará ainda mais força se evocar o benefício que os bons tratos aos animais trazem aos humanos. Recentemente, diante da epidemia de zika vírus, além de dengue e chikungunya, transmitida pelo mosquito Aedes aegypti, inúmeras postagens orbitam as redes sociais em prol da defesa das vidas dos sapos e lagartixas. O motivo? Eles comem mosquitos. Deste modo, a razão para manter sapos e lagartixas vivos não está em seu próprio direito à vida, mas no benefício, devidamente comprovado, à saúde 
humana. ${ }^{4}$ Quem considera estes bichos dignos de proteção aproveita o momento e as informações científicas para promover a necessidade de preservação de ambos.

O etologista cognitivo Mark Bekoff, por exemplo, se especializou em estudar o comportamento animal e a divulgar as capacidades cognitivas dos bichos a partir de uma perspectiva científica depois um único episódio:

\begin{abstract}
Um projeto de pesquisa para o doutorado do qual participei uma vez exigia que matássemos os gatos que estávamos estudando. No entanto, quando fui pegar "Speedo", um gato muito inteligente a quem eu secretamente tinha dado esse nome - secretamente porque não tínhamos permissão para dar nome aos "sujeitos" -, para sua última saída da gaiola, o seu destemor desapareceu completamente como se ele soubesse que era a sua última viagem. Quando eu o peguei, ele olhou para mim e perguntou, "Por que eu?". Lágrimas fluíram dos meus olhos. Ele não interrompeu o seu olhar penetrante. Embora eu tenha cumprido o meu dever e acabado com a sua vida, aquilo me deixou arrasado. Até hoje eu me lembro do seu olhar resoluto - ele me contou toda a história do seu sofrimento interminável e da falta de dignidade que tinha enfrentado (BEKOFF, 2010, p. 72).
\end{abstract}

A nova onda de proteção animal é norteada por esta realidade. Com a entrada dos animais, pelo menos alguns deles, no círculo de consideração humano e o aumento exponencial do nível de sofrimento experienciado por algumas espécies em função do nosso bem-estar, surge a necessidade de refletir sobre as formas de relacionamento entre humanos e as demais espécies. Estas interações provocam questionamentos morais, que foram levados à reflexão no âmbito da filosofia, consequentemente provocando a inserção dos bichos no rol das preocupações éticas.

No âmbito acadêmico, este movimento fica mais patente a partir da década de 70 do século passado, quando a entrada dos animais na esfera ética é reivindicada no esteio das discussões de um grupo de filósofos da Universidade Oxford, unido para investigar o status moral inferior dos bichos - entre os membros estava o filósofo Tom Regan, autor do clássico "Jaulas Vazias". No mesmo período, o estudo do comportamento animal tornou-se uma ciência: surge a Etologia Cognitiva, em 1976, quando o biólogo Donald Griffin lançou "A questão da consciência animal". Segundo Bekoff (2010, p.51-52):

\footnotetext{
${ }^{4}$ Postagem do Facebook: https://www.facebook.com/193800117422292/photos/a.255816144554022.1073741826.19380011742 2292/756508764484755/?type=3\&theater. Acesso em 15 Fev. 2016.
}

R. Inter. Interdisc. INTERthesis, Florianópolis, v.13, n.2, p.76-105 Mai-Ago. 2016 
[...] etologia cognitiva é o estudo comparativo, evolutivo e ecológico da mente dos animais. Ela se concentra no modo como os animais pensam e no que sentem, inclusive as suas emoções, crenças, raciocínio, processamento de informações, consciência e autoconsciência (BEKOFF, 2010, p.51-52).

Até então, a ética era uma das já citadas instâncias que separavam humanos de animais.

A ética é a teoria ou ciência do comportamento moral dos homens em sociedade. Ou seja, é ciência de uma forma específica de comportamento humano. A nossa definição sublinha, em primeiro lugar, o caráter científico desta disciplina; isto é, corresponde à necessidade de uma abordagem científica dos problemas morais. De acordo com esta abordagem, a ética se ocupa de um objeto próprio: o setor da realidade humana que chamamos moral, constituído - como já dissemos - por um tipo peculiar de fatos ou atos humanos (VÁZQUEZ. 2006, p.23).

A revisão que se articulava dentro e fora da academia, no entanto, apontava outros rumos. O livro "Animais, homens e moral: uma investigação sobre o maltrato de não-humanos”, de Richard D. Ryder, lançado em 1972, é um dos marcos da discussão. Em 1975, o filósofo australiano Peter Singer publicou "Libertação Animal", obra reconhecida como um dos pilares do movimento de Direitos Animais, apesar de hoje ser apropriada pela linha dos defensores do bem-estar animal ${ }^{5}$.

[...] defensores dos Direitos dos animais acreditam que eles não devem ser utilizados em laboratórios, mesmo que os benefícios ao animal ou aos humanos sejam considerados maiores que o sofrimento do animal. [...] $\mathrm{O}$ segundo grupo, liderado por Peter Singer, acredita que é aceitável que animais sejam usados por humanos, desde que de maneira responsável, com o menor sofrimento possível e que, os benefícios a outros (animais ou humanos) sejam maiores que o sofrimento do animal (CHUAHY, 2009, p.19).

Quando Singer lançou seu livro, causou uma reação forte. "Libertação Animal" trazia dados científicos que comprovavam que - por trás da desculpa de que era preciso usar os animais para o progresso e o bem-estar humanos - havia apenas

\footnotetext{
${ }^{5}$ Singer (2010) defende o princípio da igual consideração de interesses e é declaradamente tributário de Jeremy Bentham, fundador do utilitarismo moderno. Para Singer, o sofrimento do animal deve ser levado em conta e só pode ser admitido quando o benefício para os humanos for incontestável. Por isso, o autor condena as criações industriais e os experimentos científicos, por exemplo, mas não advoga contra a posição o direito de propriedade sobre os bichos. Mesmo considerado utilitarista, seu discurso hoje encontra consonância nas práticas de bem-estar animal que vêm sendo implementadas por governos ou estimuladas por organizações de defesa e proteção: "O que Singer propõe é que continuemos a tratar os animais como nossa propriedade, mas não exclusivamente como mercadorias, como é o caso sob as leis atuais do bem-estar animal (FRANCIONE, 2013, p.232).
} 
falta de consciência moral. O homem, especial e diferente por causa da razão, não usava essa qualidade tão distintiva na hora de se relacionar com os outros animais.

Práticas que eram comumente aceitas tornaram-se alvo de questionamentos. Por exemplo, quem primeiro orbitou a terra foi a cadela Laika, uma vira-lata de dois anos encontrada nas ruas de Moscou. (A HISTÓRIA, 2013). Selecionada por ser dócil, em novembro de 1957, ela foi colocada no satélite Sputnik 2 e enviada para o espaço. Durante o lançamento, Laika uivou descontroladamente e seus batimentos cardíacos ficaram três vezes acima do normal.

Em 2002, o cientista Dimitri Malashenkov, que trabalhou no projeto, detalhou o destino da cadela: o controle térmico do satélite pifou e, submetida a uma temperatura de $40^{\circ}$, Laika agonizou por sete horas até morrer. Na época, o destaque foi para a ida de um ser vivo ao espaço (PASSAGEM, 2007, p.1). Nada se disse sobre o sofrimento da cadela.

Se fosse humana, Laika seria vítima de um crime. Como era um animal, foi considerada instrumento do arsenal científico. Ainda hoje sua morte é justificada como importante para o avanço da ciência, apesar de, em 1988, o cientista Oleg Gazenko, que também trabalhou no projeto, haver afirmado que a experiência não teve utilidade para coletar dados: "Houve uma hipótese de lançar Laika - e lançamos! Faltou-nos uma análise consciente do que estávamos fazendo" (PASSAGEM, 2007, p.1).

Será que Laika e seu interesse em se manter viva não mereciam ser levados em conta? Ao longo do tempo, é possível ver que muitas posturas foram mudando a partir destes questionamentos morais e das reflexões sobre suas implicações. A exploração científica de animais passou a ser regulamentada de forma a minimizar o sofrimento:

[...] "os Três Rs" (Refine, [refinar, aperfeiçoar], Reduce [reduzir], e Replace [substituir], que são procedimentos que aperfeiçoam os procedimento que fazem mal aos animais, reduzem o número de animais utilizados e substituem, sempre que possível, os animais por outros métodos (Bekoff, 2010, p. 157).

As criações pecuárias comerciais tiveram que se adequar às políticas de bem-estar animal, transporte e abate. A World Animal Protection (antiga WSPA) faz treinamentos regulares em todo o Brasil sobre normas do chamado abate 
humanitário que inclui, entre outras medidas, práticas de transporte que diminuem a angústia do gado e a insensibilização dos animais antes da morte. A entidade estima que oito bilhões de animais no mundo teriam sido beneficiados por este modelo de produção (WSPA, 2016, p.1), apesar de este mesmo modelo levar à morte todos eles, de modo que, os realmente beneficiados, sem dúvida, foram os humanos para quem serviram de alimento.

No escopo dessas modificações, está uma variada gama de informações científicas mobilizadas por diferentes grupos. A Sociedade de Proteção Animal, por exemplo, utiliza o argumento de que a carne do animal que sofre menos é mais bem aproveitada comercialmente e que a prática eleva os lucros por transmitir uma boa impressão à sociedade em geral:

Ao longo dos últimos cinco anos, os frigoríficos que adotaram práticas de abate humanitário após nossos treinamentos melhoraram sensivelmente a sua imagem, o que os tornou mais competitivos. A redução de lesões também ajudou a diminuir perdas e a melhorar a qualidade da carne. Em um frigorífico no Brasil, por exemplo, constatou-se uma redução de até $63 \%$ dos animais com hematomas após o nosso treinamento (WSPA, 2016, p.1).

O texto acima mostra a articulação entre fato e valor ao exemplificar que a lucratividade das ações de respeito ao bem-estar animal está vinculada ao melhor aproveitamento da carne e, ao mesmo tempo, à conquista de uma opinião pública que prefere comer animais que não sofreram.

Não deixa de ser curioso que receber o carimbo de fato carrega consigo certo tipo de valor: fatos comprovados cientificamente têm valor de verdade, ainda que o conhecimento científico seja um inacabado e sujeito à refutação.

Como reforça Viana (2007, p.1), "[...] vive-se num tempo em que a ciência tem precedência e valor de verdade, um poder quase onipotente. Na atual conjuntura, ela determina ações e hábitos, justificando processo e dinâmicas humanas [...]". Um caso emblemático - e humano - é o consumo de ovo. Durante décadas, o alimento foi considerado péssimo para a saúde, pois aumentaria as taxas de colesterol ruim. Recentemente, o alimento foi reabilitado. No relatório científico do Comitê Consultivo de Orientações sobre Dieta dos órgãos norte-americanos análogos aos Ministérios brasileiros de Saúde e Agricultura o ovo agora é apontado como um alimento saudável (DIETARY, 2015, p. 541).

R. Inter. Interdisc. INTERthesis, Florianópolis, v.13, n.2, p.76-105 Mai-Ago. 2016 
Curiosamente, a constatação de que houve um engano não tira o poder do fato científico. O engano não é interpretado como tal, ele fica sufocado sob a nova descoberta, esta mais sedutora.

\section{DOMINAÇÃO DA NATUREZA}

Além do método e da separação das áreas de saber, outro pressuposto importante também já se fazia presente no período de criação e consolidação do método científico: a dominação da natureza pelo homem, movimento que definia os humanos como superiores às demais formas de vida e que vem a ser a finalidade da própria ciência.

Na história conjectural que se foi tornando mais e mais popular devido ao lluminismo europeu do século XVIII, fez-se da vitória do homem sobre outras espécies o tema central. A verdadeira origem da sociedade humana, dizia-se, estava na associação dos homens para se defenderem das feras. Depois vieram a caça e a domesticação (THOMAS, 2010, p.37).

A natureza era vista como inimiga. As bestas selvagens deveriam ser dizimadas, enquanto os animais úteis, como bois e cães, representavam aliados que poderiam contribuir para o conforto e segurança das pessoas.

O controle do homem sobre a natureza era o ideal conscientemente proclamado dos primeiros cientistas modernos. Não obstante, apesar do imaginário agressivamente despótico explícito em seu discurso de "posse", "conquista" e "domínio", eles encaravam sua tarefa, graças a gerações de pregação cristã, como inocente do ponto de vista moral (THOMAS, 2010, p.38).

Além das questões relativas aos animais não-humanos, esse período trouxe uma revisão da relação entre homem e natureza, dada a iminente crise ecológica. Rachel Carson marca o início do movimento de preservação ambiental com o livro "Primavera Silenciosa" em 1962. Cientista renomada na época, ela documentou os danos que o pesticida DDT (dicloro-difenil-tricloro-etano) causava à natureza em geral.

O mais alarmante de todos os ataques do ser humano ao meio ambiente é a contaminação do ar, do solo, dos rios e dos mares com materiais perigosos e até mesmo letais. Essa poluição é, na maior parte, irrecuperável; a cadeia de males que ela desencadeia não apenas no 
mundo que deve sustentar a vida, mas nos tecidos vivos, é, na maior parte, irrecuperável (CARSON, 2013, p. 44).

Num modelo que seria seguido posteriormente por outros autores, Carson fez um livro científico com vocabulário sem jargão específico, apesar de fundamentado em dados laboratoriais e pesquisas de campo.

Ela entrevistou centenas de colegas cientistas, funcionários de órgãos públicos ligados à agricultura, médicos que estudavam a relação entre câncer e exposição de pessoas a defensivos agrícolas. [...] o resultado foi um texto com grande embasamento científico, mas escrito de maneira apaixonada para incitar o público a exigir políticas públicas contra o uso de pesticidas sintéticos (LINS, 2012, p.84-85).

Carson uniu a escrita do jornalismo científico, da área de humanas, aos fatos científicos das ciências naturais. Originalmente, "Primavera Silenciosa" foi publicado na forma de uma série na prestigiada revista "New Yorker" (ROTHMAN, 2012, p.1). O livro de Singer também usa a estratégia de aliar o embasamento científico, prestigiado pelo senso comum, à linguagem fácil, que lhe garante a compreensão.

Apesar de toda revolução epistêmica, a crença na supremacia do fato em relação ao valor permanece em vários âmbitos, ainda que a dissociabilidade entre ambos seja questionada, como Putnam (2002) faz. O valor ainda é avaliado como algo de foro íntimo, uma idiossincrasia não passível de generalização como se pretendem as verdades científicas de fundo positivista.

Olhar as condições de vida de uma galinha num criadouro industrial e dizer que aquilo está errado poderia ser colocado na esfera do valor, pois é interpretado como um julgamento afetado pela subjetividade, além de implicar em uma lógica normativa sobre o que deve ou não ser. Consciente do prestígio da objetividade, Singer opta por uma descrição supostamente isenta de valor. Em suas palavras:

\begin{abstract}
A exemplo do capítulo anterior, para tornar as descrições o mais objetivas possível, não as baseei nas minhas observações pessoais dos locais de criação, nem das condições neles existentes. Se o tivesse feito, poderia ser acusado de descrição seletiva, tendenciosa, baseada em algumas poucas visitas a locais de criação anormalmente ruins. Ao contrário, as descrições são retiradas, em grande parte, de fontes que, espera-se, sejam as mais favoráveis à indústria de produção animal: revistas e jornais comerciais dessa indústria (SINGER, 2010, p.143).
\end{abstract}

Cabe salientarmos que, mesmo a descrição objetiva não se encontra isenta do valor semântico das palavras, como discute Putnam. Na descrição objetivada, 
temos que as galinhas ficam confinadas em cubículos de 30 centímetros quadrados, submetidas a técnicas de iluminação que as estimulam a comerem de duas em duas horas. A vida de uma galinha normal, diz Singer, dura em torno de sete anos. Estas vão para o abate em sete semanas, quando já pesam cerca de 2,5 quilos. Ao longo do período, elas apresentam comportamento agressivo porque a vida em granjas industriais vai contra a organização comunitária destas aves. "Elas não conseguem estabelecer uma ordem social e, como resultado, brigam com frequência" (SINGER, 2010, p.145).

As galinhas arrancam as próprias penas e também as de animais das "celas" vizinhas. Podem até mesmo arrancar pedaços de outras galinhas e matá-las. A solução indicada seria diminuir a superpopulação de galinhas, continua Singer, mas isso reduziria a margem de lucro. "Uma solução mais drástica, embora amplamente utilizada na indústria, é a 'debicagem'” (SINGER, 2010, p.148) - técnica de cortar a ponta do bico do pintinho numa guilhotina incandescente. Um estudo mostra que há muitos casos de narinas queimadas e grave mutilação (SINGER, 2010, p.149). Além disso:

[...] examinaram os tocos dos bicos das aves debicadas e descobriram que os nervos danificados cresciam novamente, formando uma massa de fibras nervosas entrelaçadas chamada neuroma. Os neuromas provocam dor aguda crônica no toco que resta dos seres humanos que sofrem amputação (SINGER, 2010, p.150).

Será que é mesmo preciso a opinião de cientistas para nos dizer que o que acontece com os frangos é doloroso para estes animais? Sim, pois a legitimidade do argumento está no fato. Ao se bicarem e se matarem, as galinhas estão expressando algo. Mas como ter certeza de que estão mesmo mal, se elas não podem verbalizar o desconforto? O movimento da proteção animal usa, então, a ciência como intérprete confiável daqueles que não podem falar.

Utiliza o fato - que é revestido do valor da credibilidade - para expressar um valor ético. Desse modo, vemos a utilização da crença na dicotomia fato e valor ocultando a própria inexistência da dicotomia, uma vez que o fato - ou a crença nele - expressa um valor. Para Putnam (1981), fato e valor, na verdade, se entrelaçam, ou estão imbricados, pois a verdade é construída e a prática científica pressupõe valores. Não basta que o discurso científico seja verdadeiro, ele também precisa ser 
inteligível para a sociedade a que se destina. Mais do que isso, muitas vezes, ele é adequado para determinados propósitos - neste caso para o propósito de promover as melhorias das condições de vida dos animais.

\section{A APROPRIAÇÃO DO DISCURSO CIENTÍFICO}

Como vimos, a confiança inabalável na ciência verificada em várias instâncias é também apropriada pelos movimentos de proteção animal. $O$ uso de dados científicos ajuda a embasar o discurso de respeito aos animais e dá a ele um caráter de fato.

Leis e Declarações se apoiam no fato de que os animais sentem dor, têm emoções, formas de comunicação, consciência e até mesmo código moral. É a ciência quem corrobora tais constatações. Surge então a percepção de que o animal e seus interesses tornam-se importantes a partir do momento em que a ciência Ihes atribui um determinado número de características consideradas "humanas".

Em uma palestra apresentada em 2011, o primatologista e etologista Franz de Waal, conta como começou a estudar a agressividade nos primatas e então descobriu que eles se reconciliavam. Na época, não parecia fazer sentido que ganhador e perdedor buscassem restabelecer o relacionamento, inclusive com troca de carinhos. O que ele fez nos anos seguintes foi observar e realizar testes para comprovar a cooperação entre os animais. Os experimentos conseguiram demonstrar que os chipanzés retribuíam favores.

Cientificamente, de Waal (2011) estava comprovando a reciprocidade e a empatia nos animais, dois comportamentos apontados por ele como os pilares da moralidade. Para ele, os bichos também teriam senso de justiça. Pesquisadores ofereceram pepinos a dois macacos como pagamento pela realização de uma tarefa simples. Tudo certo até que um deles começava a ser pago com uvas. Aquele que recebia o pepino claramente se revoltava: batia no acrílico da sua gaiola e esticava o braço, batendo na mesa de testes.

Franz de Waal comenta que economistas, políticos e filósofos criticaram muito o estudo. "Eles haviam decidido em suas mentes, eu acredito, que justiça era um 
sentimento muito complexo e animais não poderiam tê-lo", disse de Waal (2011). Alguém argumentou que só haveria senso de justiça se o macaco beneficiado com uvas exigisse que o colega também recebesse pagamento igual. $E$ isso aconteceu: alguns macacos recusavam as uvas até que o companheiro também recebesse.

O cientista não nega que os seres humanos estão em uma escala mais evoluída de moralidade, mas usa seus estudos para comprovar que outros animais têm código moral. Além de empatia e senso de justiça, apresentam reciprocidade e tendência a consolar.

Quando a condição subjetiva de um ser vivo ganha o peso do fato, da certeza, é mais fácil garantir o reconhecimento de direitos. O valor do fato científico pôde ser comprovado recentemente: em julho de 2012, um grupo internacional de neurocientistas, neurofarmacologistas, neurofisiologistas, neuroanatomistas e neurocientistas computacionais cognitivos assinou a Declaração de Cambridge sobre a Consciência em Animais Humanos e Não Humanos. No documento, eles afirmam:

\begin{abstract}
A ausência de um neocórtex não parece impedir que um organismo experimente estados afetivos. Evidências convergentes indicam que animais não humanos têm os substratos neuroanatômicos, neuroquímicos e neurofisiológicos de estados de consciência juntamente como a capacidade de exibir comportamentos intencionais. Consequentemente, o peso das evidências indica que os humanos não são os únicos a possuir os substratos neurológicos que geram a consciência (DECLARAÇÃO, 2012, p.1).
\end{abstract}

O líder do grupo, Philip Low, resumiu em uma frase a necessidade do gesto: "não podemos mais dizer que não sabíamos" (PIRES, 2012, p.1). É a ciência quem dá o alerta e a palavra final: não se pode mais alegar ignorância sobre o estado de consciência dos animais para justificar maus tratos.

Selecionamos um caso específico, ocorrido no Brasil, para analisar as questões que envolvem e articulação fato e valor e a busca por ações/políticas que garantam a proteção dos animais não-humanos. 


\section{A HISTÓRIA DE SCOOBY}

O caso dos cães com leishmaniose visceral mostra que o discurso baseado na sensibilidade é insuficiente. $O$ tratamento para leishmaniose visceral em cães é proibido pelo Governo Brasileiro, mas muitos protetores defendem o tratamento dos animais, com a manutenção da vida. O procedimento é feito clandestinamente, com medicamentos para humanos: o nível de parasitose nos animais baixa consideravelmente, mas não chega a zero.

Se um mosquito picar o animal infectado, há risco, mesmo que pequeno, de transmissão da doença para outro animal - humano ou não-humano. Para reduzir essa possibilidade, os animais recebem uma coleira especial que repele o mosquito vetor e vivem em locais com rígido controle ambiental.

Em outros países, existem remédios veterinários para a leishmaniose canina e a eutanásia é proibida. Os laboratórios que fabricam os medicamentos atuam no Brasil, mas não têm licença para vender o produto aqui, por isso uma alternativa adotada pelos tutores de animais doentes é utilizar a versão do medicamento indicada para humanos (COSTA, 2014, p.1).

Para proteger animais infectados, os discursos éticos usam a retórica científica para Ihes conferir crédito. Ou seja, quem quer proteger os cachorros com leishmaniose por questões morais e afetivas busca fatos científicos que amparem o discurso ético de proteção aos animais. Da mesma forma, aqueles que acreditam nos riscos para a saúde pública utilizam a ciência como forma de justificar suas posições e atingir seus objetivos. Cada grupo usa a ciência como melhor the convém. Lacey (2006) lembra que a avaliação empírica não oferece uma certeza absoluta, pois mais investigações podem originar novos resultados, por isso em muitos casos, confiar num discurso científico envolve uma tomada de lado, já que a imparcialidade não é absoluta ou até mesmo possível.

Há um caso que queremos destacar como paradigmático para os argumentos que sustentamos: o destino do cachorro Scooby, de Campo Grande (MS). Em julho de 2012, apresentando sintomas de leishmaniose, ele foi amarrado a uma moto pelo próprio dono e arrastado por quatro quilômetros até o CCZ - Centro de Controle de 
Zoonoses do município (DONO AMARRA, 2012, p.1). Chegou ao local sangrando muito, com as patas em carne viva.

O dono de Scooby foi levado à delegacia por maltrato ao animal. $\mathrm{O}$ homem garantiu à imprensa que não fez por maldade. Poderia ter abandonado o cachorro na rua. Em seu favor, usou a mais cartesiana das afirmativas: não imaginava que o animal sofreria ao andar quatro quilômetros naquelas condições (NÃO FIZEMOS, 2012).

Scooby foi diagnosticado com leishmaniose em agosto, quando seu drama já havia corrido o país. Ele passou a contar com o apoio de entidades de proteção e de amantes de animais do Brasil inteiro. O governo, no entanto, não se compadeceu: Scooby deveria ser morto. Uma campanha para impedir a eutanásia começou na internet e na cidade.

Naquele curto período, o cachorro triste e coberto de feridas já apresentava uma pelagem dourada e a postura acuada sumiu. Note-se que essa última observação pode ser acusada de antropomorfização e atribuída apenas à sensibilidade, o que, tecnicamente, a invalida. Segundo Araújo e Lima (2002): "o fato de olharmos para um cachorro e julgarmos sua aparência estar triste pode ser explicado pela projeção que fazemos de uma interpretação a partir de outros gestos e atitudes do animal" (ARAÚJO; LIMA, 2002, p.230).

$\mathrm{O}$ prefeito autorizou que Scooby fosse poupado somente depois que uma especialista o convenceu da segurança do tratamento. A presidente do Conselho Regional de Medicina Veterinária do município à época, Sibele Cação, defendeu o tratamento do animal e forneceu argumentos científicos suficientes para garantir mais tempo de vida ao cachorro. Ela acabaria perdendo o cargo por defender o cão.

Em dezembro de 2012, o prefeito voltou atrás: Scooby deveria ser levado ao CCZ para ser examinado. No mês seguinte, a ONG que cuidava do cachorro entrou na Justiça para reavê-lo, temendo a eutanásia. A Justiça decidiu em favor da ONG. Poucos dias depois, a partir de uma ação movida pela mesma entidade, o Tribunal Regional Federal da $3^{a}$ Região autorizou o tratamento de cães com leishmaniose. $O$ órgão considerou que proibir o uso do medicamento de humanos em animais seria um incentivo ao extermínio de cães. A decisão foi válida para todo país 
(VASCONCELOS, 2012). O Ministério da Agricultura rebateu: "Essa prática pode tornar o parasita causador da doença resistente às drogas atualmente disponíveis" (VASCONCELOS, 2013, p.1).

Um novo argumento entrava no jogo: a resistência do parasita. Mas a justiça continuou decidindo em favor de Scooby. Depois de inúmeras tentativas de contato com a atual tutora do animal, Sibele Cação, conseguimos notícias dele por meio de um voluntário da ONG: até setembro de 2015 Scooby estava vivo, bem e muito forte.

A saída para o impasse de Scooby parece repousar na ciência. Pesquisadores do Instituto de Ciências Biológicas da Universidade Federal de Minas Gerais desenvolvem um tratamento que alcançou a cura parasitológica da leishmaniose visceral canina em $50 \%$ dos casos. Todos os animais submetidos ao protocolo terapêutico deixaram de transmitir o parasita para o mosquito, interrompendo o ciclo de transmissão para o homem (ARAÚJO, 2012) Em todas as matérias coletadas e analisadas foram expostos motivos científicos favoráveis e contrários à eutanásia (DA MATA, 2013; EM TRATAMENTO, 2012; JUSTIÇA, 2013; NÂO FIZEMOS, 2012; QUEIROZ, 2012; ESPECIALISTA, 2013). Os sentimentos de Scooby nunca foram colocados em pauta. Sua vida é mantida pelo equilíbrio de teorias científicas. Mas será que a vida de Scooby vale o risco para outras pessoas e animais?

Confrontado com essa pergunta em uma Audiência Pública, realizada em março de 2013, em Campo Grande (MS), o doutor em parasitologia e professor de doenças infectocontagiosas, Vitor Márcio Ribeiro, disse que a saúde humana é mais importante que a do animal. No entanto, afirmou que a eutanásia não reduz a doença e que o tratamento com remédio para humanos neutraliza, sim, o potencial de transmissão da doença pelo cão. Ou seja, quem brigou para que Scooby ficasse vivo foram pessoas sensibilizadas pela sua condição e defensoras do seu direito à vida, mas o que pesou na decisão a favor de Scooby foram os argumentos científicos. Se não houvesse a confiança na eficácia do tratamento, haveria muito pouco em que apoiar a sobrevida do cão. 


\section{CONSIDERAÇÕES}

Gray (2006) argumenta que a ciência ganhou uma importância tão grande na sociedade atual que não pode rivalizar com a experiência cotidiana. Ao fim da análise do caso de Scooby, ficou a constatação que as sensibilidades tiveram pouco peso. Os argumentos éticos ganharam algum espaço, mas foram os fatos científicos que garantiram a sobrevida do cão. Dizer que Scooby ficou feliz por estar vivo é uma avaliação que estaria elencada na esfera dos valores, mas mantê-lo vivo porque a ciência nada atestava a favor de sua morte, tem outro peso.

Assim, é justo dizer que a mesma ciência que consolidou a separação entre homens e animais também opera no sentido contrário. Darwin trabalhou nesta perspectiva, afirmando que a diferença entre humanos e não-humanos era de grau e não de gênero, questão curiosamente rechaçada por muito tempo nas ciências humanas, que trabalham com valor e não com fatos, mas nem por isso são menos antropocêntricas.

A razão e o método científico, heranças da modernidade, marcam os modos de pensar os animais e suas relações com os seres humanos e, ainda que tais paradigmas venham sendo questionados, como demonstramos neste artigo, os fundamentos da razão, objetividade e experimentação continuam hegemônicos. Em uma sociedade que supervaloriza a certeza, os estudos das ciências naturais servem de selo para haver credibilidade nas informações sobre o comportamento animal e assim favorecem transformações também no comportamento humano a ele relacionado.

Em consequência, abordamos também como, a partir de sensibilidades individuais e questionamentos morais, os animais são inseridos na esfera das considerações éticas e o discurso científico é apropriado pelos movimentos em favor dos animais devido ao seu caráter legitimador. O caso do cachorro Scooby, um animal contaminado por leishmaniose, foi analisado para consolidar esta reflexão sobre a relação entre sentimentos, considerações morais, princípios éticos e ciência e como tais conceitos interatuam no movimento de proteção aos animais. 
Apesar das transformações epistêmicas, as fronteiras na relação entre homens e animais continuam sendo construídas. Como é próprio da condição de fronteiras, elas separam, mas também aproximam ciências humanas e naturais, que começam a se entrelaçar na organização de novas relações entre humanos e nãohumanos.

R. Inter. Interdisc. INTERthesis, Florianópolis, v.13, n.2, p.76-105 Mai-Ago. 2016 


\title{
BETWEEN SPECIES AND SCIENCES: A REFLECTION ABOUT THE SCIENTIFIC ARGUMENTATION PRACTIVE TO LEGITIMIZE THE ANIMAL CAUSE
}

\begin{abstract}
:
Throughout modernity, scientific knowledge is established as the only true knowledge and some principles underlie its practices, among which we highlight the goal of domination of nature, the supremacy of the human species and the epistemological validity of fact. Nevertheless, the discoveries made by science enabled the questioning of some of its own grounds, such as human supremacy, and thus engendered the development of animal welfare arguments based on facts. In this context, the aim of this paper is to discuss how the development of knowledge about animals and their human relations has contributed to transformations of ethical emplacements that underlie the everyday actions. Through the dog Scooby case analysis, we see that despite some changes, human life has the privilege on the lives of other species.
\end{abstract}

Keywords: Humanities. Animal Studies. Interdisciplinarity. Animal Rights. Scientific Culture.

\section{ENTRE ESPECIES Y CIENCIAS: UNA REFLEXIÓN SOBRE LA UTILIZACIÓN DE ARGUMENTOS CIENTÍFICOS PARA LA LEGITIMACIÓN DE LA CAUSA ANIMAL}

\section{Resumen:}

A lo largo de la modernidad, el conocimiento científico se establece como el único conocimiento verdadero y varios principios fundamentan sus prácticas, entre las que destacamos el objetivo de la dominación de la naturaleza, la supremacía de la especie humana y la validez epistemológica de este hecho. Sin embargo, los descubrimientos de la ciencia permitieron al cuestionamiento de algunos de sus propios fundamentos, tales como la supremacía humana, y por lo tanto engendraron el desarrollo de los argumentos de defensa de los animales, también basadas en hechos. En este contexto, el objetivo de este trabajo es discutir cómo la construcción de un conocimiento sobre los animales y sus relaciones con los humanos ha contribuido a las transformaciones de fundamentaciones éticas que subyacen en las acciones cotidianas. A través del análisis del caso del perro Scooby, vemos que a pesar de los cambios mencionados, la vida humana tiene el privilegio en la vida de otras especies.

Palabras-clave: Humanidades; estudios animales; interdisciplinaridad; derechos animales; cultura científica. 


\section{REFERÊNCIAS}

A HISTÓRIA de Laika: progresso ou crueldade? Dog Dicas. São Paulo, 2013. Disponível em: www.dogdicas.com.br/1532/a-historia-de-laika-progresso-oucrueldade. Acesso em:18 abr. 2013.

ALMEIDA, N. As três culturas na universidade nova. Ponto de Acesso, v. 1, n.1, p. $5-15.2007$.

ARAÚJO, A. R. O caminho da cura. Boletim UFMG, n 1773, ano 38, 2012. Disponivel em: www.ufmg.br/boletim/bol1773/6.shtml. Acesso em: 16 abr. 2015.

ARAÚJO, R; LIMA, R. Contribuições da etologia comparada para uma nova percepção da comunicação humana. Margem, n.15, p. 223-236, 2002.

BEKOFF, M. A vida emocional dos animais: alegria, tristeza e empatia nos animais: um estudo científico capaz de transformar a maneira como os vemos e tratamos. São Paulo: Cultrix, 2010.

CARSON, R. Primavera silenciosa. São Paulo: Gaia, 2013.

CHALMERS, Alan. O que é ciência afinal? São Paulo: Editora Brasiliense, 1993.

CHUAHY, R. Manifesto pelos direitos dos animais. São Paulo: Record, 2009.

CHAUÍ, M. 2013. Filosofia moderna. Disponível em:

http://www.cfh.ufsc.br/ wfil/chaui.htm . Acesso em: 03 jul. 2013.

COMTE, A. COMTE: Coleção Os Pensadores. São Paulo : Abril Cultural, 1978.

COSTA, D. Leishmaniose tem tratamento, mas medicamento é proibido no Brasil. Belo Horizonte: Encontro BH, 2014. Disponível em: http://sites.uai.com.br/app/noticia/encontrobh/atualidades/2014/05/08/noticia atualid ades, 148573/leishmaniose-tem-tra tamento-mas-medicamento-e-proibido-nobrasil.shtml. Acesso em 16 fev. 2015. 
DA MATA, F. Cão diagnosticado com leishmaniose é devolvido a ONG em MS. 2013. Rio de Janeiro: Globo.com. Disponível em http://g1.globo.com/mato-grossodo-sul/noticia/2013/01/cao-diagnosticado-com-leishmaniose-e-devolvido-ong-emms.html. Acesso em: 08 jul. 2013.

DECLARAÇÃO de Cambridge sobre a consciência em animais humanos e nãohumanos. Documento disponível em <http://www.ihu.unisinos.br/noticias/511936declaracao-de-cambridge-sobre-a-consciencia-em-animais-humanos-e-naohumanos >. Acesso em: 20 out. 2012.

DIETARY Guidelines Advisory Committee (Estados Unidos). Secretary Of Health And Human Services/secretary Of Agriculture. Scientific Report 2015. Washington Dc: Dhhs/usda, 2015. 571 p.

DONO amarra cão em moto e o arrasta por $4 \mathrm{~km}$, diz delegada em MS. Rio de Janeiro: 2012. Globo.com. Disponível em http://g1.globo.com/mato-grosso-dosul/noticia/2012/07/dono-amarra-cao-em-moto-e-o-arrasta-por-4-km-diz-delegadaem-ms.html. Acesso em: 07 jul. 2013.

EDELMAN TRUST BAROMETER. 2015. São Paulo: Edelman. Disponível em http://www.slideshare.net/fullscreen/EdelmanInsights/2015-edelman-trust-barometerbrazil/1. Acesso em: 15 fev.2015.

EM TRATAMENTO contra leishmaniose, Scooby apresenta melhoras em MS. Rio de Janeiro: Globo.com. 2012. Disponível em http://g1.globo.com/mato-grosso-dosul/noticia/2012/08/em-tratamento-contra-leishmaniose-scooby-apresenta-melhorasem-ms.html. Acesso em: 07 jul. 2013.

ESPECIALISTA diz que cachorro tratado não transmite a Leishmaniose.

Cassilândia: Cassilândia Notícias. 2013. Disponível em

http://www.cassilandianoticias.com.br/ultimas-noticias/especialista-diz-que-cachorrotratado-nao-transmite-a-leishmaniose. Acesso em: 08 jul. 2013.

FRANCIONE, G. Introdução aos direitos animais: seu filho ou o cachorro? Campinas: Editora Unicamp, 2013.

GRAY, J. Cachorros de palha: reflexões sobre humanos e outros animais. Rio de Janeiro: Record, 2006. 
IANNI, O. A polêmica sobre ciências e humanidades. In SEMINÁRIOS UNICAMP: Diversidade na ciência, 2003, Campinas. Anais... Campinas: UNICAMP, 2003.

INGOLD, T. Humanity and animality. In: INGOLD, Tim (Org.) Companion encyclopedia of anthropology. Tradução de Vera Pereira. Londres: Routledge, 1994. Disponível em

http://www.anpocs.org.br/portal/publicacoes/rbcs $00 \quad 28 /$ rbcs28 $05 . \mathrm{htm}$

JUSTIÇA mantém decisão e deixa Scooby com ONG em Campo Grande. Dourados: Folha de Dourados. 2013. Disponível em http://www.folhadedourados.com.br/noticias/estado-regiao/justica-mantem-decisaoe-deixa-cao-scooby-com-ong. Acesso em: 08 jul. 2013.

LACEY, H. Relações entre fato e valor. Cadernos de Ciências Humanas, v.9, n.16, p. $251-266,2006$.

LINS, C. Cinco décadas de consciência ecológica. Pesquisa Fapesp, n.202, p. 84 85, 2012.

MARICONDA, P. O controle da natureza e as origens da dicotomia entre fato e valor. Scientiae Studia, v. 4, n. 3, p. 453-72, 2006.

MERCHANT, C. The Death of Nature. 2. ed. New York: Harper \& Row, 1991. O caminho da cura. Minas Gerais: Boletim UFMG. Disponível em https://www.ufmg.br/boletim/bol1773/6.shtml. Acesso em: 17 fev. 2015.

'NÃO FIZEMOS por maldade', diz suspeito de arrastar vira-lata em MS. Rio de Janeiro: Globo.com. 2012. Disponível em http://g1.globo.com/mato-grosso-dosul/noticia/2012/07/nao-fizemos-por-maldade-diz-suspeito-de-arrastar-vira-lata-emms.html. Acesso em: 07 jul. 2013.

O MERCADO de 14 Bilhões de Reais. Negócios Pet. São Paulo, 2013. Disponível em http://www.rnpet.com.br/materias-mercado-de-14-bilhoes.php. Acesso em: 25 jul. 2013.

PIRES, M.T. "Não é mais possível dizer que não sabíamos", diz Philip Low. São Paulo: Veja On-line. 2012. Disponível em http://veja.abril.com.br/noticia/ciencia/naoe-mais-possivel-dizer-que-nao-sabiamos-diz-philip-low. Acesso em: 20 jul. 2012. 
PASSAGEM só de ida para Laika. 2007. São Paulo: Scientific American.

Disponível em

http://www2.uol.com.br/sciam/noticias/passagem so de ida para laika.html.

Acesso em 10 jul. 2013.

PINKER, S. Os anjos bons da nossa natureza - porque a violência diminuiu. São

Paulo: Companhia das Letras, 2013.

PUTNAM, H. Reason, truth and history. Cambridge: Cambridge University Press, 1981.

PUTNAM, $\mathrm{H}$. The collapse of the fact/ value dichotomy and other essays.

Cambrige, 2002, MA: Harvard Press.

Queiroz, T. Prefeitura em MS autoriza que Scooby faça tratamento contra leishmaniose. Rio de Janeiro: Globo.com, 2012. Disponível em http://g1.globo.com/mato-grosso-do-sul/noticia/2012/07/prefeitura-em-ms-autorizaque-scooby-faca-tratamento-contra-leishmaniose.html. Acesso em: 07 jul. 2013.

ROTHMAN, J. 2012. Rachel Carson's natural histories. New York: The New Yorker. Disponível em http://www.newyorker.com/online/blogs/books/2012/09/rachelcarsons-natural-histories.html. Acesso em: 15 maio 2013.

SINGER, P. Libertação animal. São Paulo: Editora WMF Martins Fontes, 2010.

THOMAS, K. O homem e o mundo natural: mudanças de atitude em relação às plantas e aos animais (1500 - 1800). São Paulo: Companhia das Letras, 2010.

VASCONCELOS, N. Decisão da Justiça Federal autoriza tratamento de cães com leishmaniose. Campo Grande: Campo Grande News. 2012. Disponível em http://www.campograndenews.com.br/cidades/capital/decisao-da-justica-federalautoriza-tratamento-de-caes-com-leishmaniose. Acesso em: 08 jul. 2012.

N. Após liminar, Ministério reforça veto ao tratamento de cães com leishmaniose. Campo Grande: Campo Grande News. 2013. Disponível em http://www.campograndenews.com.br/cidades/apos-liminar-ministerio-reforca-vetoao-tratamento-de-caes-com-leishmaniose. Acesso em: 08 jul. 2013. 
VÁZQUEZ, A. S. ÉTICA, São Paulo: Civilização Brasileira, 2006.

VIANA, M.. Divagação científica vs. divulgação científica. São Paulo: Observatório da Imprensa, 2007. Disponível em

http://www.observatoriodaimprensa.com.br/news/view/divagacao cientifica vs divul gacao cientifica. Acesso em: 20 abr. 2012.

VOLTAIRE, F. Dicionário Filosófico. [e-book] Disponível em http://www.dominiopublico.gov.br/pesquisa/DetalheObraForm.do?select action=\&co obra $=2253.2001$. Acesso em: 10 jul. 2012.

DE WAAL, F. de. Palestra Moral behavior in animals. TEDxPeachtree, em novembro de 2011.

WASP. Animais de produção. 2015. Disponível em:

<http://www.worldanimalprotection.org.br/nosso-trabalho/animais-de-producao $>$. Acesso em: 25 jan. 2016

\section{Artigo}

Recebido em 29 de Outubro 2015

Aceito em 07 de Abril de 2016 